\title{
"Laboratorio Abierto": un importante recurso de enseñanza
}

Nilton Alves

La búsqueda de metodologías de enseñanza y nuevas técnicas didácticas con el objetivo de desarrollar habilidades ha sido siempre una preocupación para los docentes del área de salud.

El proyecto 'Laboratorio Abierto' mostró claramente que la demanda de visitas al Laboratorio de Morfología por colegios de las redes pública y privada de la VII Región, en Chile, fue intensa.

El objetivo era proporcionar a estudiantes de enseñanza media la oportunidad de tener contacto con la morfología y fisiología humanas, así como recibir información sobre la carrera de odontología, y además, posibilitar a estudiantes de odontología la oportunidad de desarrollar sus habilidades en la elaboración y presentación de ponencias.

En el inicio del año lectivo 2010, dos estudiantes voluntarios de la carrera de odontología fueron entrenados para llevar a cabo charlas, con una duración media de 50 minutos, sobre temas relacionados con el cuerpo humano. En estas charlas, dirigidas a estudiantes de enseñanza media de la VII Región, se brindaba información sobre la carrera de odontología. Luego, los visitantes eran conducidos al Laboratorio de Morfología, donde recibían demostraciones en microscopios y piezas cadavéricas.

Los dos estudiantes universitarios se beneficiaron del proyecto, ya que tuvieron que profundizar sus conocimientos para armar la presentación y responder a las preguntas presentadas. Los colegios que participaron del proyecto proporcionaron a sus estudiantes la oportunidad de observar especímenes anatómicos preparados con diferentes técnicas y piezas cadavéricas con variaciones anatómicas, anomalías y patologías. Además, 400 estudiantes de enseñanza media pudieron aclarar sus dudas sobre los temas tratados, incluso obteniendo información relevante que contribuyó a la elección más consciente de la carrera profesional.

Las actuales orientaciones didácticas consideran formatos diversos, entre ellos, los que buscan atender a los objetivos procedimentales, que persiguen el desarrollo de determinadas destrezas intelectuales en relación con los procesos científicos. La visita a laboratorios permite la interactividad del estudiante, lo que propicia una contribución importante en su formación.

El proyecto 'Laboratorio Abierto' presentó un balance muy positivo, lo que pudo confirmarse por su continuidad y por el interés de las escuelas atendidas. Su éxito se evidenció con informes de estudiantes que optaron por odontología y declararon que fueron motivados en tomar esta decisión después de la participación en el proyecto. Los estudiantes participantes de la carrera de odontología se declararon muy motivados en seguir en el proyecto no sólo por la satisfacción que encontraron en la difusión de conocimientos, sino también por la mejora de su rendimiento para hablar en público. Además, este proyecto permitió la interactividad del estudiante, lo que contribuye a su formación.
CIMA Research Group. Universidad de La Frontera. Temuco, Chile.

E-mail: niltonnalves@yahoo.com.br (c) 2014 FEM 